\title{
Thoughts on Dealing with Climate Change...As if the Future Matters
}

\author{
Michael H. Glantz ${ }^{1}$ and Ilan Kelman ${ }^{2, *}$ \\ ${ }^{1}$ Consortium for Capacity Building, INSTAAR, University of Colorado, Boulder, CO 80309, U.S.A. \\ ${ }^{2}$ Center for International Climate and Environmental Research - Oslo, N-0318 Oslo, Norway
}

\begin{abstract}
This article uses the need for more inspiration in people to act on climate change as a basis for exploring some thoughts on the societal and environmental challenges of climate change. It aims to provide ways of interpreting what is often presented on climate change without considering how the audience receives that information and might or might not be inspired to take action based on it. Different meanings of "change" are examined in the context of "climate change." The term "adaptation" is similarly analyzed. Based on the understanding of those terms, four notions are defined and outlined in relation to decision-making for climate change adaptation: Ignorance versus "Ignore-ance," surprise, foreseeability, and forecasting by analogy. The conclusions explore the interlinkages between society and the environment as well as how to turn lessons identified into lessons that are actually learned in order to be implemented. Achieving inspiration is not straightforward, but without it, the future will be bleak under a changing society and environment.
\end{abstract}

Keywords climate change, climate change adaptation, climate change forecasting, climate change impacts

\section{Climate Change and the Lack of Inspiration to Act}

The United Nations Environment Programme (UNEP) has as its mission "To provide leadership and encourage partnership in caring for the environment by inspiring, informing, and enabling nations and peoples to improve their quality of life without compromising that of future generations" (UNEP 2013, 100). The "-ing" words are particularly important: inspiring, informing, and enabling. Today, much of environmental work, especially regarding climate, is about information and action. There is often an assumption that with enough information about environmental problems and solutions, action will immediately follow.

The flaws of that assumption are well-documented (McKercher et al. 2010), even for scientists themselves (Stohl 2008), in that the information-to-action connection is neither linear nor well-established. One of the missing elements

\footnotetext{
* Corresponding author. E-mail: ilan_kelman@hotmail.com
}

might be the third goal in UNEP's mission statement: to be inspiring.

Rather than a rational, systematic approach to observing the world and then thoughtful action in order to make a better world, perhaps we need more inspiration: people doing what is needed because they want to, because they feel passionate about it, and because they intuitively are driven to follow what they have come to believe.

This article explores some thoughts on the societal and environmental challenges of climate change through presenting and critiquing vocabulary and notions that are taken for granted, even though such notions might be contributing to the lack of action. It aims to provide ways of interpreting what is often presented on climate change without considering how the audience receives that information and might or might not be inspired to take action based on it.

\section{Change}

It is important to explore the word "change," especially in the context of "climate change." It seems that, aside from those groups dealing specifically with scientific climate change issues on a more or less daily basis, most people are uncertain regarding what is meant by climate change. That is especially the case since climate science notes that climate is constantly changing on all time scales: year-to-year, decade-to-decade, century-to-century, and beyond. The general public often refers to "climate change" when they mean to refer to unexpected climate variations on seasonal, interannual, and longer time frames. "Change" and "variability" can be used synonymously in general parlance about climate.

For so-called "experts," "climate change" has two different, common definitions. The Intergovernmental Panel on Climate Change (IPCC), a UN-affiliated group for synthesizing and summarizing the science on climate change, defines the term to be "any change in climate over time, whether due to natural variability or as a result of human activity" (IPCC 2007, 871). The United Nations Framework Convention on Climate Change (UNFCCC), responsible for negotiations regarding international treaties on climate change, defines the term to be "a change of climate which is attributed directly or 
indirectly to human activity that alters the composition of the global atmosphere and which is in addition to natural climate variability observed over comparable time periods" (UN 1992, Article 1, Paragraph 2). That is, the scientific view takes climate change to be all climate trends, irrespective of the origin of those trends, while the policy measures focus on anthropogenic climate change. IPCC and UNFCCC definitions of climate change differ at the basic level, yielding detrimental consequences for trying to support responses to "climate change" (Pielke Jr. 1998, 2005).

When "climate change" discussions reach the public, the media, and elected officials, their confusion is understandable. They have a right to ask: Which change in climate is being talked about and what does "climate change" actually mean?

Depending on location and livelihoods, climate changing in some way at some time and space scales may be welcomed. A somewhat warmer winter with less snow might seem positive to many Minnesotans. Many of the ramifications might not be considered, such as what happens to the other seasons, how ecosystems respond, and the resulting changes to recreation, tourism, pests, and mold. A $2-3^{\circ} \mathrm{C}$ average warmer winter in places which are normally just below freezing can change snow into freezing rain and ice, making roads and sidewalks perilous while bringing down trees and power lines from the ice's weight.

Thus, the word "change" when associated with climate has different, sometimes contradictory, meanings and implications for various observers, depending on what they are considering and what they seek in their location for living and working. One way to try to reduce the confusion is to separate those climate "changes" that we have been living with and adjusted to over seasons, years, and decades, from climate "changes" that society has not seen in millennia-perhaps never since human settlement. That will be the case for the changes expected to accompany a human-influenced global warming of the atmosphere in many Arctic locations.

Some literature suggests "dangerous" climate change as the phrase to use (Schneider 2001), but that has been debated extensively and does not really resolve the challenges noted above. Another possible suggestion, amongst many, would be the use of the notion of "deep" climate change (Fischer 1996) to represent the profound type of change that many scientists now say that future generations will likely need to adjust to.

As the climate changes and society adjusts, it is not just about climate change. There are other changes as well. Population is increasing and its distribution is shifting towards urban settings, especially megacities, rather than the rural or small town basis under which humanity developed. Technology is another factor, such as hand-held mobile devices becoming increasingly prevalent, even in megacity slums without running water or sewage along with remote farming areas where people have their own generators rather than reliable electricity.

As society and technology change, expectations and lifestyles change. People in more affluent countries seek increasing amounts of leisure time and enjoy the luxury of cheap flights for holidays and shopping, while fully knowing and accepting the contribution of that energy use to climate change and lack of sustainability. Adapting to climate change, as well as other forms of change to the climate, takes place within these wider contexts of societal change-and adjustments sometimes result in zero net gain for sustainability.

It is not just the change itself that needs to be taken into consideration. Rates of change are as important as the type and direction of the change, particularly because society tends to respond more quickly and comprehensively to rapid changes than to slow changes. Yet the latter can often do much more damage over the long term, as well as being potentially preventable since there is time to act as the consequences are manifesting. Glantz (1994a, 1994b) refers to "creeping environmental changes," "creeping environmental problems," and "creeping environmental phenomena" (CEPs). CEPs are small, often incremental but cumulative changes to environmental conditions which, over time, add up to create major problems, often witnessed as a crisis or disaster once an undefined threshold has unwittingly been surpassed (see also Glantz 1999). CEPs include desertification, soil degradation, salinization of water supplies, and climate change.

"Creeping social changes" or "creeping social phenomena" can be as important. The internet did not become a household service overnight. It took two decades from its initial appearance for the first internet structure to become engrained in workplaces. Over the subsequent two decades, a shift was seen from dial-up internet to dedicated high-speed internet lines to wireless. Electricity has been common for more than a century, but it is just over the past decade or so that wireless electricity has become common.

Creeping changes do not preclude sudden (abrupt, step-like) changes, such as the earthquake that levels a city or the assassination that leads to a dictatorship or democracy. All changes are part of what drives society to change and the changes to which society must adapt. Change does not occur in a societal vacuum and each change can spark and influence other changes that need to be addressed as well.

Focusing on creeping changes and rates of change instead of searching for a "dread factor" (such as a step-like adverse climate change impact) to spark policy changes can be one approach to communicating what needs to be done - and to inspiring action for doing that. That is particularly the case because "climate change" and its consequences have often been seen and interpreted as something happening in the future - namely future decades of the 21 st century - even though it is being witnessed now. Indigenous peoples from places in the Arctic and low-lying islands are reporting major environmental changes now that were expected under climate change at some time in the future (see http://www. manystrongvoices.org).

The phrase that captures these challenges is "The future is arriving earlier than expected!" Climate change projections long into the future are appearing in places now. What does that mean for the rest of the world? It means that "creeping" 
is actually not so creeping, but is on top of us now. What we initially thought would happen in several decades, seems to be manifesting over several years, such as the models of sea ice reduction under climate change underestimating what is seen in reality; observations of sea ice today are what the models projected would be seen in several years (Stroeve et al. 2007). Put another way, "2020 is likely to be the new 2050." Demonstrating immediate or imminent changes can help in communicating what "change" means, how "climate change" is relevant, and what needs to be done in awareness-raising and in response.

\section{Adaptation}

Similar discussions are needed for the word "adaptation" which has been taken over by climate change researchers and now policymakers, after long use in research fields such as biology (Darwin 1859). Yet people have always adapted and adjusted to environmental changes at many time scalesnamely climate variability, trends, and changes - in tandem with adapting and adjusting to social changes.

$\operatorname{IPCC}(2007,76)$ defines "adaptation" to be "Initiatives and measures to reduce the vulnerability of natural and human systems against actual or expected climate change effects. Various types of adaptation exist, e.g. anticipatory and reactive, private and public, and autonomous and planned. Examples are raising river or coastal dikes, the substitution of more temperature-shock resistant plants for sensitive ones, etc." UNFCCC (2012) defines "adaptation" to be "Adjustment in natural or human systems in response to actual or expected climatic stimuli or their effects, which moderates harm or exploits beneficial opportunities."

These definitions are more similar than for "climate change," yet still highlight the complexities and challenges in different approaches to climate change. IPCC's (2007) definition distinguishes between different types of adaptation, which in turn need further explanation and discussion. UNFCCC (2012) effectively just defines "adaptation" as being "adjustment" to climate, which humanity has done for millennia. The term "adjustment" has also long been in the scientific vocabulary regarding humanity dealing with climate and weather (White 1942/1945), so it is unclear why a new definition for a word, with a long non-climate history, was suddenly introduced. IPCC's (2007) definition also seems to imply that adaptation deals with only negative impacts, whereas UNFCCC's (2012) definition, in line with IPCC's previous approach (Pielke, Jr. 1998), states specifically that exploiting climate's "beneficial opportunities" is part of adaptation.

The obvious question of what is needed to inspire people to change voluntarily needs to be further detailed from the basis of the definitions: Adaptation to what? The definitions use phrases such as "expected climate change effects" (IPCC 2007, 76) and "actual or expected climatic stimuli or their effects" (UNFCCC 2012). As with "change," "climate" and "climatic stimuli" do not have the same meaning to all people.
Many languages do not even have words for "to adapt" nor do they differentiate between "climate" and "weather," making it difficult to explain to people that they must "adapt" to "changing weather" over the long term!

Even IPCC $(2007,78)$ admits confusion over the word "climate":

Climate in a narrow sense is usually defined as the average weather, or more rigorously, as the statistical description in terms of the mean and variability of relevant quantities over a period of time ranging from months to thousands or millions of years. The classical period for averaging these variables is 30 years, as defined by the World Meteorological Organization. The relevant quantities are most often surface variables such as temperature, precipitation and wind. Climate in a wider sense is the state, including a statistical description, of the climate system. In various parts of this report different averaging periods, such as a period of 20 years, are also used.

"A statistical description" can be interpreted differently. Much more information than just the average (a statistical mean) of variables could be included, such as median, mode (that is most frequent occurrences), ranges, and extremes. Fully understanding "climate" means including seasonal to interannual variability, climate fluctuations and trends on the decade and century scales, climate change, extreme events, and seasonality. Seasonality is purposely separated out from variability because most people, whether rural or urban, live according to the expected characteristics and flow of the seasons. Even in more affluent countries, seasonality is important: putting on snow tires and airing out the radiator are hardly part of one's summer routine.

Any relatively high impact event or extreme, such as a prolonged drought or flood that disrupts the flow of the seasons, tends to disrupt human livelihoods and ecological processes. The late onset of the rainy season or the early termination of rains can adversely disrupt the expected flow of the seasons. Even more affluent countries provide examples: in North American cities, the first snowfall, whether in September or December, is notorious for snarling traffic - as if a snowfall does not happen every year.

When we deal with adapting to climate change, we are acting beyond our seasonal routines and expectations and beyond previously experienced variability. Instead, both IPCC (2007) and UN (1992) refer to a new global climate state, contrasting with what humanity has come to assume is "normal," despite always having experienced climate trends and variability. But "adaptation" is not just a "solution"-it can also be a problem creator.

Adapting to climate change is not a one-time effort. Climate goes through changes on all time scales meaning that societies are constantly adjusting to variable and changing global-to-local climate regimes. That is why continual monitoring of social and environmental conditions, with effective early warning when necessary, is important. Societies must be sensitized to change direction - to be inspired to adapt and adjust - as more information is acquired and as the climatesociety-environment knowledge base is further expanded. 
But adaptation itself generates its own set of societal consequences. To make adaptation efforts more effective, governments must simultaneously identify and prepare for the ripple effects of their adaptation measures. For climate change, migration is described as both an adaptation response and a failure to adapt (Foresight 2011). Despite eviscerating critiques of the entire notion (Hartmann 2010), extensive literature continues to be published on the topic, but much of it lacks thorough examination of the ripple effects beyond predictions of conflict. Climate change's consequences for identity, culture, sovereignty, and ecosystems deserve much more attention.

Each proposed adaptation response to climate variability, extremes, or change must (not "could" or "should") be accompanied by statements about the proposer's awareness of the likely downstream, second-and-third order effects of the proposed adaptive measure. That creates an awareness that adaptation generates a cascade of its own impacts that might require adjustments (adaptations?) as well-possibly along the lines of "mitigating the impacts of adaptation"!

\section{Decision-Making}

\subsection{Ignorance versus "Ignore-ance"}

Despite the huge amount of academic and media coverage on climate change, many decision-makers and policymakers, along with many in the general public, still do not have extensive knowledge about climate change, its impacts, or how to deal with the impacts. That is especially the case for people who, unlike indigenous peoples in the Arctic and many people on low-lying islands, do not feel that they are being directly affected right now. While recognizing the tenuous link between knowledge and action, many people are nonetheless ignorant of the science of climate change. Even for those who are interested in the science and have quite a bit of knowledge, their perceptions of the urgency and severity of the problem are not always in line with what the science says. Those with the power to act can frequently lack the training and information that they need in order to better understand and respond to the impacts from and actions for climate change. They, too, can be said to be ignorant.

This level of ignorance is, to some degree, understandable, given that decision-makers and policymakers are generally not specialists. They are confronted by issues to which they must respond and they always seek a balance of needs among various political pressures. That ignorance, though, can be overcome in theory by getting their attention for a while to provide more information, even if extensive lobbying is required to achieve that.

A different and more challenging problem is "ignoreance." Ignore-ance refers to those with the power, as well as their followers, who already have the basic information and understanding which they need regarding climate change, its potential consequences, and actions to avert those consequences - but they purposely choose to ignore that knowledge. The reasons that they ignore it can vary, such as not believing in science; not caring about climate change and its consequences; focusing on short-term benefits for increasing their re-election chances; their sponsors (such as the coal and oil industries) telling them what to do; and pandering to the ignorance of their constituents who do not have the time or the inclination to sort out the implications of climate change issues.

Ignore-ance is harder to overcome than ignorance. If a large portion of an electorate brings enough pressure to bear on the elected officials, then there might be a chance of those with the power reversing their ignore-ance and acting on their knowledge. But strong incentives, particularly seeking shortterm gains and not wishing to change lifestyles, exist for both those with the power and the public to deliberately continue in ignore-ance.

Ignorance is not knowing something while ignore-ance is knowing something and not caring about it. Those who are ignorant can be inspired to learn; those with ignore-ance can be hard to inspire to action. The two fundamental lessons for those who wish to avoid both ignorance and ignore-ance are: What you don't know and what you ignore can still hurt you, as climate change will if no action is taken; and Don't believe everything you think, but instead, try to get full information and then to act on that information in order to actively avoid ignore-ance while minimizing your own ignorance.

\subsection{Surprise}

"Surprise" is a strange word. Often, it is not used in accordance with its original meaning. The following definitions of surprise are paraphrased from the Oxford English Dictionary.

- The act or an act of encountering something unexpectedly or suddenly, or of being taken unawares.

- An unexpected or unanticipated occurrence or event; something astonishing or full of wonder.

- The feeling or emotion due to the unexpected or due to an occurrence for which one is unprepared.

- Alarm, terror, or perplexity caused by suddenness.

A key element of the different dictionary definitions of "surprise" is the word "unexpected." Yet there are "knowable surprises," though that might seem contradictory. Taking the example of drought and drought response for sub-Saharan Africa, there are aspects which are often articulated as being surprises to governments and the media, yet are certainly knowable and known:

- Droughts, defined here as less rainfall than is needed for favorable crop production or for sufficient rangeland vegetation, often seem to catch governments unprepared to deal with them. Yet drought in subSaharan Africa is a foreseeable and usual occurrence, even if localized manifestations and impacts are rare for the people affected - or their traditional coping mechanisms have been undermined (Fleuret 1986). 
- During an El Niño event in the Pacific Ocean, there is an increased likelihood (but not a certainty) of drought in sub-Saharan Africa, especially the Horn of Africa and Southern Africa.

- Food shortages are often the result of inappropriate land-use policies. There are many examples of people and governments being encouraged to grow crops that are not suited to the local or regional climate conditions. Growing wheat on irrigated farms in Northeastern Nigeria is a good example because a wheat crop is more sensitive to adverse changes in rainfall and temperature in arid and semiarid areas than traditional dryland crops such as millet and sorghum.

- In many agricultural areas, there is competition between growing food crops for local markets and subsistence, and cash crops for export markets. Subsistence crops feed people but cash crops (such as qat or cotton) are grown for sale elsewhere. Farmers are paid for their cash crops, but if there is a drought and cash crop production falls sharply, then they have no food to eat or money to buy food in the local marketplace. That contrasts with having preserved food from their subsistence crops and using a diversity of crops including drought-resistant ones, amongst other traditional techniques (Fleuret 1986).

- Often, irrigation schemes are built to grow cash crops for export, which continue during droughts, even in countries with severe food shortages.

- During prolonged droughts, often high-interest rate loans have to be repaid either in cash or in kind (such as by working on the fields of the lender) by those who had to borrow seeds for planting, food for the family, or funds to buy food. This creates and perpetuates an unequal relationship between the lenders and the borrowers. The borrower may have to work in the fields of the lender at critical planting and harvesting times, at the neglect of the borrower's own fields.

- The trigger for identifying a drought problem varies. Some people know a food problem is starting by looking at the crop conditions in the field while others wait for signs of severe shortages such as people abandoning their villages in search of food.

- Not all food aid goes to those in need. There are examples where food aid has been diverted by governments to keep the army loyal or has ended up being sold on the black market.

- Pledges by donor governments to provide food aid are often not met. Many governments do not always follow through on their assistance pledges.

- Many of the at-risk people with the highest vulnerability to drought and malnutrition are known before a drought strikes, because they are the groups subject to the chronic vulnerability to most hazards: the poorest people, pregnant women, the elderly, and children.

- It is well known that, in many places, the time of the year just prior to harvesting is known as the hunger season. People are hard at work in the fields, but their household food reserves tend to be at their lowest levels and their nutritional needs cannot be met.

- During severe food shortages, population movements increase. Preparations can be made well in advance, focusing on keeping people in or near their villages by providing food and funds.

Each of these "surprises" is experienced continually and is well-known. While governments, development banks, and donor agencies might claim surprise when drought impacts appear, strategic long-range monitoring and planning would avoid the perceived suddenness and scramble to deal with an emergency.

Knowable surprises are not just limited to less affluent locations. Hurricane Katrina struck the U.S. Gulf Coast in 2005 causing the death of close to 2000 people and apparently catching local, state, and national emergency managers by surprise. The flooding of New Orleans, Louisiana, in particular, seemed to be a surprise. The head of the U.S. Federal Emergency Management Agency (FEMA) at the time, Michael Brown, was not even prepared to travel at short notice to any emergency situation, let alone the areas hit by Katrina, despite that being his job. While the floodwaters were still rising, he wrote e-mails trying to find a dog sitter for himself so that he could travel to the damaged locations. A disaster in the United States on his watch was apparently such a surprise that he had no contingency plans for his pet!

Yet, everything that happened because of Katrina was knowable and was known. Aside from previous storms striking the area in 1947, 1965, 1969, and 1998, the flooding of New Orleans was previously described (Fischetti 2001) and emergency plans to deal with hurricane-related evacuation existed (OEP 2000). The year before Hurricane Katrina, FEMA had conducted an exercise known as Hurricane Pam. From 16-23 July 2004 in Louisiana, hundreds of emergency response officials from all three levels of government simulated landfall of a Category 3 hurricane along the Louisiana shoreline, leading to several meters of flooding in New Orleans with over one million people evacuated and up to 60,000 people killed (Committee on Homeland Security and Governmental Affairs 2006).

Little of what was learned from the Hurricane Pam scenario was carried out the next year as Katrina bore down on New Orleans. Hurricane Katrina made landfall on the edge of Categories 3 and 4, after over one million people had evacuated, and led to several meters of flooding in New Orleans. It was a knowable surprise which could have beenand actually was - foreseen.

\subsection{Foreseeability}

In his law dictionary, Gifis (1991, 195-196) writes that "Foreseeability encompasses not only that which the defendant foresaw, but that which the defendant ought to have foreseen." The notion of foreseeability comes from law and can be 
interpreted as a qualitative expression of probability, in order to determine accountability or fault when someone has been injured or killed (or property has been damaged). That clearly applies to disasters as well, meaning that foreseeability is relevant for dealing with the potential hazards of climate variability, extremes, and change and foreseeing which adaptation measures should be implemented and when.

It is reasonable to expect that there are likely to be adverse consequences from people's vulnerability to the hazard of climate and its changes on various time scales, especially if steps are not taken to reduce that vulnerability. Do those with the power to act beforehand have a legal, if not moral or political, responsibility for the resulting climate impacts? The case study by Holloway (2000) of the impending drought in southern Africa from 1991-1993 is instructive. The famine consequences of the drought were foreseeable. Those with the power to act took heed, led a massive food import and distribution effort, and averted a catastrophe.

Similar foreseeability was not acted on in mid-2002 when an El Niño-related drought and potential food shortages were warned about as being a strong possibility for Zimbabwe (Glantz and Cullen 2003). The background was previous years of political changes in land ownership and land use, linked to and part of dictatorial and corrupt governance from Robert Mugabe, indicating that food production was expected to decline across the country. Then, came a forecast for the onset of El Niño later that year with a strong potential for drought across southern Africa, starting in the growing season and continuing into 2003. Foreseeing a strong possibility of severe food shortages in Zimbabwe, as well as in other countries across the region which depend on Zimbabwe's food exports, was straightforward.

Despite the foreseeability, Mugabe and his government did little to avert the crisis (see background and details in Howard-Hassmann 2010). By October 2003, 50 percent of Zimbabwe's population was unable to meet their food needs. The food shortages continued for several years, particularly as Mugabe continued to interfere with farming, food distribution, and humanitarian aid. The leaders in power in Zimbabwe chose not to avert the foreseeable and preventable disaster. This was clearly a case of political ignore-ance at the highest levels of government.

We know what the impacts of climate variability and extremes are and what those of climate change could be. They are foreseeable, yet needed action is not being taken even though we know now how to act. As with Zimbabwe, ignore-ance is clear.

\subsection{Analogy}

One way to try to inspire action is through analogies. Analogies comprise a base and a target, with the base representing what we already have or know while the target is what we are trying to understand or wish to know (Gentner 1983). Analogies can be used for (1) educating and providing information, particularly to connect with an audience through something which they know already; (2) parameterizing complex processes; (3) forecasting future states, trajectories, or possibilities for a system; (4) generating and describing policy options and responses; and (5) fulfilling a psychological need.

Analogies are useful for describing climate change and its impacts, particularly in terms of demonstrating what might happen in the future, that is, "forecasting by analogy" (Glantz 1988). Forecasting by analogy is not about giving definite answers regarding future states of the atmosphere under climate change or regarding future states of society under climate change. Instead, it describes how societies have dealt with environmental changes previously, taking into account different degrees and rates of change, for applying that knowledge to what is expected under climate change in the future in order to work with society now to avoid detrimental consequences.

Decision- and policymakers often need real-world, tangible examples to understand what they face, particularly precedents (Neustadt and May 1986). Forecasting by analogy can give a reality to projections, imbuing credibility lacking in computer-generated scenarios or speculative descriptions.

As an example of using forecasting by analogy to address potential climate change impacts, the Cod Wars between Iceland and the United Kingdom can be examined. These countries had three major disputes over cod, which have been termed the Cod Wars. In 1958, Iceland unilaterally extended its fishing limits from 4 miles to 12 miles off its coastline. The United Kingdom objected, but was unable to change the situation. In 1972-1973, Iceland unilaterally extended its fishing limits to 50 miles leading to a two-year agreement between Iceland and the United Kingdom which limited the latter's fishing rights within Iceland's 50-mile limit. The end of that agreement led to the third war in 1975-1976. Iceland unilaterally extended its fishing limits to 200 miles leading to confrontations between Icelandic and British ships, including rammings, a few shots, and some crew injuries. As with the first two wars, the United Kingdom conceded the third war by permitting Iceland to control the claimed zone (Glantz 1992).

Two of England's cities significantly affected by the Cod Wars were Kingston-upon-Hull (shortened to "Hull") on the north shore of the Humber Estuary and Grimsby on the south side of the Humber Estuary. The sudden restriction of fishing in Iceland's rich waters severely limited the fishing-based livelihoods of these two cities. That led to significant livelihood changes in both locations: a transfer of livelihoods to other sectors, migration, and reliance on social services. Fisheries, the basis of both towns previously, are no longer significant for either place, although fish-related manufacturing is making a small comeback in Grimsby.

In terms of using the Cod Wars as an analogy for climate change impacts on fishing livelihoods, towns in Norway, for example in the Lofoten archipelago above the Arctic Circle, are expected to experience sudden changes in fisheries as climate change warms the ocean's waters and changes food supplies. Without any substitution of new fish for the fish 
currently exploited, as was the case for Hull and Grimsby, the Norwegian towns are likely to experience the same impacts as the English towns: a transfer of livelihoods to other sectors, migration, and reliance on social services. Presumably the first change, livelihood transfer, is preferable to the other two changes, migration and welfare.

Norwegian towns can use forecasting by analogy to be inspired to plan for the foreseeable changes, rather than being forced into them by surprise, as were Hull and Grimsby. Neither ignorance nor ignore-ance should be an excuse to not thinking ahead of foreseeable changes.

\section{Society and Environment Dealing with Change: Beyond Lessons}

The Millennium Ecosystem Assessment (MEA 2005) was a major IPCC-like undertaking to assess "the consequences of ecosystem change for human well-being." It embodied the ethos that there is self-interest in protecting ecosystems because of the goods and services that the ecosystems provide, part of the value system that ecosystems must "pay their way to survive" in a profit-driven globalized world. A tropical forest would be at risk of being chopped if it did not provide maximum benefit to a particular society - and that society is usually defined globally rather than locally.

An ecosystem that was considered to be expendable by policymakers is demonstrated by the demise of the Aral Sea in Central Asia. It was decided by those in power in the 1950s in the Soviet Union that a cubic meter of water to irrigate cotton production on desert sands was a hundred times more valuable than keeping the fish in the sea alive. As a result of that calculation, water from the two mighty regional rivers feeding the Aral Sea-the Amu Dar'ya and Syr Dar'ya Rivers-were diverted in such great quantity from entering the sea in the name of cotton production that, in a classic creeping environmental change, the fourth largest inland sea in the world in 1960 was significantly dried up after a few decades (Glantz 1999).

The phrase "ecosystem goods and services for human well-being" is part of the problem. Humans need the ecosystems much more than the ecosystems need humans. The complementary phrase "human goods and services for ecosystem well-being" must be considered at the same time in terms of what humanity can provide for ecosystems to survive- or, better, how ecosystems and humanity must work together for each one's survival.

Along the same line of reasoning, it is time to stop separating society from the global climate system as many physical scientists are likely to do. Human activities influence atmospheric behavior as a result of the gases added through industrial and land-use practices, as well as a result of interfering with biogeochemical cycles through land-use practices that change atmospheric sinks for gases. Society, through changing sources and sinks of trace gases in the atmosphere, now has major influences on atmospheric composition and, hence, on climate. In this regard, society becomes like the planet's physical features, being one more influence along with forests, oceans, and volcanoes, amongst others.

Such lessons, and others throughout this article, can be encapsulated in the phrase "lessons learned," derived from the belief that individuals and societies learn from their decisions that produced either good or bad outcomes - or both. An English adage is "Once burned, twice shy," capturing a belief that we learn from our experiences, and that we want to learn from our experiences, especially bad ones that we wish to avoid repeating. Frequently with respect to disasters, close scrutiny of recommendations reveals that the lessons are really only identified, not actually learned. To be learned, the lessons must be implemented so that a change for the better is seen. Because they are called "learned," there is an assumption that the lessons are being addressed, when in fact, other issues perceived to be more urgent often appear and take over the agenda. Attention and funds are diverted away from the ongoing disaster recovery-and from the lessons identified regarding how to prevent disasters.

As an example (Glantz and Jamieson 2000), Hurricane Fifi slammed into Honduras in 1974, killing thousands of people and setting back development decades. In the aftermath, many lessons were identified about reconstructing to a less vulnerable state than before and dealing with hurricanes in the future. In 1998, Hurricane Mitch devastated similar parts of Honduras, killing thousands and setting back development decades. The lessons were not learned in that they were not implemented. Instead, they were merely identified and then society moved onto other tasks, with the armed conflicts across Central America being prominent, until the next hurricane hit and the same lessons were re-identified.

One approach for trying to focus on lessons learned rather than lessons identified is connecting each lesson or recommendation to a statement of "ramification"; that is, a statement of the foreseeable outcome if the lesson or recommendation is not heeded. That would provide a measure of accountability if no action were taken on the lessons identified and adverse results recurred in the future. That would hopefully also provide a measure of inspiration to demonstrate what could be avoided by taking appropriate action.

When it comes to dealing with a changing climate and a changing society, humanity, our leaders, and us as individuals have needed roles to play. Climate change is not just about the physical aspects of the climate system, but envelops a much broader scope since humanity is an integral part of that system. Humanity can no longer be passive about climate change, or merely "adapt" to the external changes happening within the physical climate system. Instead, humanity must be proactive as part of what could be termed "the greater climate system," a system including society and society's actions.

Achieving that is not straightforward. Education, training, awareness, and knowledge exchange still seem to lack success at a large scale in terms of inspiration; mainly in terms of inspiring people to move from a passive role to an active one. 
That includes chipping away at both ignorance and ignoreance to try to avoid plausible surprise. That includes using analogies to understand possible changes, thereby incorporating foreseeability into everyday actions and decisions. That means learning from the past without becoming a slave to it, to implement the lessons known and identified, without forgetting that new factors might be present and might emerge later. That will assist in a creative, innovative, flexible society which does not merely adapt to societal and environmental changes, but lives and thrives with them.

\section{References}

Committee on Homeland Security and Governmental Affairs. 2006. Preparing for a Catastrophe: The Hurricane Pam Exercise. Hearing before the Committee on Homeland Security and Governmental Affairs. United States Senate, One Hundred Ninth Congress, Second Session, 24 January 2006. Washington, DC: Committee on Homeland Security and Governmental Affairs.

Darwin, C. 1859. On the Origin of Species by Means of Natural Selection, or the Preservation of Favoured Races in the Struggle for Life. London: John Murray.

Fischer, D. H. 1996. The Great Wave: Price Revolutions and the Rhythm of History. New York: Oxford University Press.

Fischetti, M. 2001. Drowning New Orleans. Scientific American 285 (4): 76-85.

Fleuret, A. 1986. Indigenous Responses to Drought in Sub-Saharan Africa. Disasters 10 (3): 224-229.

Foresight. 2011. Migration and Global Environmental Change: Final Project Report. London: The Government Office for Science.

Gentner, D. 1983. Structure-Mapping: A Theoretical Framework for Analogy. Cognitive Science 7 (2): 155-170.

Gifis, S. 1991. Law Dictionary, 3rd edition. New York: Barron's Educational Series.

Glantz, M. H. 1988. Societal Responses to Regional Climatic Change: Forecasting by Analogy. Boulder, CO: Westview Press.

Glantz, M. H. 1992. Global Warming Impacts on Living Marine Resources: Anglo-Icelandic Cod Wars as an Analogy. In Climate Variability, Climate Change and Fisheries, edited by M. H. Glantz, 261-290. Cambridge: Cambridge University Press.

Glantz, M. H. 1994a. Creeping Environmental Problems. The World \& I, June: 218-225.

Glantz, M. H. 1994b. Creeping Environmental Phenomena: Are Societies Equipped to Deal with Them? In Creeping Environmental Phenomena and Societal Responses to Them, edited by M. H. Glantz, 1-10. Proceedings of Workshop held 7-10 February 1994 in Boulder, Colorado. Boulder, CO: NCAR/ESIG.

Glantz, M. H., ed. 1999. Creeping Environmental Problems and Sustainable Development in the Aral Sea Basin. Cambridge: Cambridge University Press.

Glantz, M. H., and H. Cullen. 2003. Zimbabwe's Food Crisis. Environment 45 (1): 9-11.
Glantz, M. H., and D. Jamieson. 2000. Societal Response to Hurricane Mitch and Intra versus Intergenerational Equity: Whose Norms Should Apply? Risk Analysis 20 (6): 869-882.

Hartmann, B. 2010. Rethinking Climate Refugees and Climate Conflict: Rhetoric, Reality and the Politics of Policy Discourse. Journal of International Development 22 (2): 233-246.

Holloway, A. 2000. Drought Emergency, Yes ... Drought Disaster, No: Southern Africa 1991-1993. Cambridge Review of International Affairs 14 (1): 254-276.

Howard-Hassmann, R. E. 2010. Mugabe's Zimbabwe, 2000-2009: Massive Human Rights Violations and the Failure to Protect. Human Rights Quarterly 32 (4): 898-920.

IPCC (Intergovernmental Panel on Climate Change). 2007. IPCC Fourth Assessment Report. Geneva: IPCC.

McKercher, B., B. Prideaux, C. Cheung, and R. Law. 2010. Achieving Voluntary Reductions in the Carbon Footprint of Tourism and Climate Change. Journal of Sustainable Tourism 18 (3): 297-317.

MEA (Millennium Ecosystem Assessment). 2005. Millennium Ecosystem Assessment, Ecosystems and Human Well-Being. Washington, DC: Island Press.

Neustadt R. E., and E. R. May. 1986. Thinking in Time: The Uses of History for Decision-Makers. New York: Free Press.

OEP (Office of Emergency Preparedness). 2000. State of Louisiana Emergency Operations Plan, Supplement 1A: Southeast Louisiana Hurricane Evacuation and Sheltering Plan (Revised January 2000). Baton Rouge: Louisiana Office of Homeland Security and Emergency Preparedness.

Pielke Jr., R. A. 1998. Rethinking the Role of Adaptation in Climate Policy. Global Environmental Change 8 (2): 159-170.

Pielke Jr., R. A. 2005. Misdefining "Climate Change": Consequences for Science and Action. Environmental Science \& Policy 8 (6): 548561.

Schneider, S. H. 2001. What Is "Dangerous" Climate Change? Nature 411 (6833): 17-19.

Stohl, A. 2008. The Travel-Related Carbon Dioxide Emissions of Atmospheric Researchers. Atmospheric Chemistry and Physics 8 (21): 6499-6504

Stroeve, J., M. M. Holland, W. Meier, T. Scambos, and M. Serreze. 2007. Arctic Sea Ice Decline: Faster than Forecast. Geophysical Research Letters 34 (9), Article No. L09501.

UN (United Nations). 1992. United Nations Framework Convention on Climate Change. FCCC/INFORMAL/84 GE.05-62220 (E) 200705. Bonn: UN.

UNEP (United Nations Environment Programme). 2013. 2012 Annual Report. http://www.unep.org/Documents.Multilingual/Default.asp? DocumentID $=43$.

UNFCCC (United Nations Framework Convention on Climate Change). 2012. Glossary of Climate Change Acronyms. Bonn: UNFCCC. http://unfccc.int/essential_background/glossary/items/3666.php.

White, G. F. 1942/1945. Human Adjustment to Floods: A Geographical Approach to the Flood Problem in the United States. Doctoral Dissertation, University of Chicago (1942) and republished as Research Paper No. 29 (1945), University of Chicago, IL, Department of Geography.

Open Access This article is distributed under the terms of the Creative Commons Attribution License which permits any use, distribution, and reproduction in any medium, provided the original author(s) and source are credited. 